\title{
Using Facebook to Develop Grammar Discussion and Writing Skills in English as a Foreign Language for University Students
}

\author{
Mervat Abd Elfatah Ali Said Ahmed \\ Oklt Alsqoor College of Science and Arts, Qassim University, Qassim, Saudi Arabia
}

\begin{abstract}
This study aimed at investigating the effect of Facebook on grammar discussion and writing skill in English as a foreign language for university students. The study sample consisted of 60 students at Oklt Al Sqoor College of Science and Arts in Saudi Arabia and was divided into two groups: 30 students for the experimental group and 30 students for the control group. The instrument of the study was an EFL grammar and writing test. Students in both the experimental and the control group were pre-tested using the EFL (English as a Foreign Language) grammar and writing test. After that the experimental group was taught using Facebook while the control group was taught using the traditional method. Finally, students in both groups were post-tested using the EFL grammar and writing test. Results of the study showed that the experimental group outperformed the control group in the post-test of EFL grammar and writing. This difference can be attributed to using Facebook.
\end{abstract}

Keywords: Facebook, grammar discussion, writing skill, English as a foreign language

\section{Introduction}

Writing is an important but difficult skill to acquire, a communication skill which is essential in today's information society. The level of difficulty is significantly higher when a foreign language (FL) is involved. Differences in the language structures, the manner of expressing thoughts, writing styles, and other culturally varying factors greatly affect the writing of foreign language learners (FLL) (Benson \& Heidish, 1995).

In many Arab countries including Egypt and Saudi Arabia, the education systems emphasize writing for taking tests. For many students, the only reason to practice writing is to pass examinations or to get a good grade in the course. From students' viewpoints, this reduces the value of writing to developing a written product and receiving a grade from the teacher. This approach is not likely to make students interested in writing, which becomes decontextualised and artificial, giving them no real sense of purpose or perspective of a target audience. In this respect, some studies in Egypt and Saudi were conducted offering different approaches and remedial programs to overcome the decontextualization of writing and develop some EFL essay writing skills (El-Hibir \& Al-Taha, 1992; Abdou, 1993; Abdel-Gawad, 2003; Abdel-Razek, 2006).

Grammatical knowledge plays a significant role toward the meaning and the quality of the written text. In writing, the student cannot get immediate feedback. The student needs to write carefully because the reader does not exactly stay in that place. Therefore, written language needs to be well-prepared and understandable. As one of the criteria for grading the quality of writing, the ability to use grammar, and as a result, grammar has been taught widely in school throughout the world (Hinkel, 2004). This is because grammatical knowledge not

Mervat Abd Elfatah Ali Said Ahmed, assistant professor, Ph.D., Oklt Alsqoor College of Science and Arts, Qassim University. 
only helps the writer understand the conventions of Standard English but also reduces their use of vernacular or non-standard English (Haussamen, Benjamin, Kolln, \& Wheeler, 2003).

Grammatical errors in subject-verb agreement, subject omission, indirect questions, various forms of "other", the article "the", prepositions, word choice, and verb forms can cause big troubles in writing (Herrero, 2005). Meanwhile, conjunctions, references, and tenses not only have their own functions, but also enable a text to show some particular kinds of meanings (Schleppegrell, 1998). Due to the significant role of grammar in writing improvement, there are both in-class and online teaching methods developed to enhance grammatical knowledge and subsequently to enhance writing abilities of students. Facebook is used as online teaching method to develop EFL university student grammar discussion and writing skill.

Facebook is a global large social media that boosts more than 100 million followers, and it is one of the fastest-growing and best-known sites on Internet these days. Initiated and established by Zuckerberg in 2004, Facebook as a network at first targeted high school and college students but it goes globally and actively gains its popularity of all people ages (Blattner \& Fiori, 2009). Facebook has been a leading social media currently.

Many features such as the "like" button, comment application, and sharing button in Facebook have attracted users to create discussion and share their thoughts instantly. In line with Facebook tagline "giving people the power to share and making the world more open and connected" creates space for autonomy and engagement in exchanging ideas and knowledge due to active roles consumed by learners (Ashton \& Newman, 2006). In Facebook, users can have their own group of interests, share and exchange messages between them via the available applications easily (Kwong, 2007). One of the available applications is that "My Notes" provide users with opportunities to write and blog almost anything under the sun (Kwong, 2007).

The interactive feature of Facebook is believed to provide students with great opportunities to practice their writing. In other words, students post their written pieces, receive comments, write and post their own comments, and reply to other Facebook group members. Therefore, this interactive communication enables students to actively engage in the writing process and improve their writing skills. Also, the computer-based grammar checkers and spelling checkers that students use from time to time while interacting on Facebook groups, are considered to be powerful ways of providing immediate feedback on their written output. Further, the use of Facebook is deemed to have a positive impact on boosting students' motivation and attitude (Kabilan, Ahmed, \& Abidin, 2010).

Facebook has been a platform for students to write in a way which is different from the writing done in school for academic purposes. Students regard the in formal writing outside school (including Facebook, blogs, and Twitter) as "communication" and the school writing as "writing", which is an exercise in test taking (Yancey, 2009). The students are unable to see the connection between the two forms of writing (inside and outside school) and, the students are unable to consider writing as an enlarging activity to express themselves as well as a tool to perform in academic situations.

However, even though grammar and writing are worth promoting, previous studies have not placed much emphasis on how Facebook can be used as a medium for developing English grammar and writing skill. To address the lack of research, the present study explored the effect of using Facebook as a medium for developing English grammar discussion and writing skill of EFL students at the university level.

To understand how Facebook affects grammar and writing, it is better to understand the underlying learning theory of Facebook:. 


\section{Learning Theories}

Constructivism. Facebook is a Web 2.0 social networking site. According to Ferdig (2007), Web 2.0 technology is rooted in constructivist principles. The essence of constructivism lies in the belief that learning is a social process. (Lave \& Wenger, 1991). "The distance between the actual development which is determined by independent problem solving and the level of potential development as determined through problem-solving under adult guidance or in collaboration with more capable peers" (Wertsch \& Viste, 2005, p. 57). In brief, students will be able to learn more if they receive proper assistance from a more advanced person. This assistance is referred to as scaffolding in constructivist terminology. Therefore, if students write collaboratively in Facebook, constructivism holds that, they will be able to progress through their zone of proximal development with scaffolding from the teacher or more able peers. Therefore, they are to improve and develop "higher cognitive function".

Wenger (1998) believes that learning occurs best through communities of practice. In such a community, learning evolves out of meaning negotiation and finding, mutual engagement in action, community building, and identity construction. That is, members interact, "do things together, negotiate new meanings, and learn from each other" in communities of practice (Wenger, 1998, p. 102) and this will promote learning.

Collaborative writing. From a social constructivist perspective then, learning activities should be designed to promote co-construction of knowledge. Writing collaboratively according to these theories, should help learners write better. Collaborative writing in simple terms can be defined as two or more people working together to produce a document with group responsibility for the end product. Collaborative writing is quite promising and has brought out a multitude of benefits: It increases grammatical accuracy, overall writing quality and improves lexis and discourse. Students are exposed to valuable input from others and they are encouraged to produce enhanced output and provide feedback for themselves and peers (Storch, 2005; Oxford, 1997).

Social networking sites are a potential ground for online collaborative writing. They are a "range of applications that augment group interactions and shared spaces for collaboration, social connections, and aggregate information exchanges in a web-based environment" (Bartlett-Bragg, 2006; Usluel, 2010, p. 445). Ajjan and Hartshorne (2008) believe that "Using Web 2.0 technologies such as Facebook to supplement in-class instructions could create an interactive and collaborative learning experience for students in a media they are familiar with".

Previous studies. Rifai (2010) aims to investigate the relationship between students' attitudes on the use of Facebook and blog as learning tools in writing class. Two groups of students were made as experimental and control group. The experimental group used Facebook and blog as learning tools for 13 sessions while the control group only used Binusmaya, local multi channel learning. Students' attitudes were gathered through survey and the results were compared to their final test scores. The result showed that students' lack of enthusiasm was in line with students' level of achievement in writing and that Facebook and blog gave significant influence on improving students' writing competence.

Shih (2011) examined the effectiveness of incorporating blended learning approach with Facebook and peer assessment for college writing class by conducting an experimental study with 23 English majored freshmen at a technological university in Taiwan. Both research instruments for quantitative (i.e., pretest and posttest of English writing skills; student surveys) and qualitative methodologies (i.e., in-depth student 
interviews) were employed in the study. Data analysis showed that integrating Facebook and peer assessment with blended learning can be interesting and effective for English writing courses at tertiary level because it helps students enhance their writing skills both in class meetings and virtual cooperative learning environment.

Yusof, AbManan, and Alias (2012) investigate using Facebook Notes as the medium of providing peer feedback to students' written work. Planning, drafting, revising, and editing are the four stages involved in a writing process. Guided peer feedback via the Facebook Notes could assist the teachers in ensuring that all the students' writing pieces are reviewed at all the four stages of the writing process and consequently improved the quality of their written work. The first part of this action research explored the use of peer feedback at the planning stage of writing which was outlining. It was found that the students, with guidance from the writing teacher, were able to provide constructive feedbacks to their peers. The comments and suggestions posted on the Facebook Notes were found to be useful in helping their peers to improve their outlines and their first draft. Language teachers also could benefit this new tool in giving feedbacks to the students.

Yen, Hou, and Chang (2012) investigate the effectiveness of utilizing the role-playing instructional strategy in EFL teaching of writing with Facebook as the medium through which it is conducted. This study was conducted on 12 students registered in an English Business course in a university from Northern Taiwan. The findings of this study indicate that the use of role-playing strategy in combination with Facebook as the platform result in meaningful improvements in the students' language acquisition and learning experience.

Melor, Salehi, Sun, Yen, and Li (2012) examine the students' perceptions on the use of Facebook groups in teaching ESL writing. The students' perceptions were measured through a questionnaire comprising 10 close-ended items. The respondents were 43 students in TESL, in the Faculty of Education, University Kebangsaan Malaysia (UKM). Respondents were also required to participate in a Facebook group called "Write out Load" which was created by the researchers. The findings indicated that Facebook groups can be effective in teaching ESL writing. The results showed that the students can learn new vocabularies from reading the comments of others in the group, and the spell-check feature helps reduce their spelling errors.

Wichadee (2013) explores how integrating a social networking website called Facebook with peer feedback in groups supports student learning, investigates the nature of feedback students received on their writing, and examines their attitudes towards the use of Facebook for peer feedback. The study involves 30 undergraduate students who participated in giving and receiving feedback on Facebook with an aim to develop their writing competence over the fundamental English course of one-semester study. Data were collected from the first and final drafts of writing assignments, written peer comments, a questionnaire, and an interview. The results revealed that the nature of students' feedback focused on content more than grammatical errors. However, quantitative analyses of the peer comments and revisions to the drafts showed that feedback given on Facebook had an effect on improving revised drafts. There was statistically significant improvement in the revised drafts which was linked to peer feedback. Finally, the analysis of interviews indicated positive attitude on the use of Facebook for peer feedback in the English class.

Shukor and Noordin (2014) investigated the effects of Facebook collaborative writing groups on ESL undergraduates writing performance. A total of 33 second year ESL students were involved in this study. The comparison between face-to-face and Facebook collaborative writing groups were made in order to measure students' writing performance on the intervention based on Jacob's et al. (1981) ESL Composition Profile; content, organization, vocabulary, language use, and mechanics. The findings of the study showed that participants in Facebook collaborative writing groups displayed slightly higher scores compared to face-to-face 
collaborative writing groups.

Bani-Hani, Al-Sobh, and Abu-Melhim (2014) investigate the perceptions and attitudes of Jordanian EFL students' at Irbid University College-Al-Balqa' Applied University towards utilizing Facebook groups in teaching writing. It also seeks to investigate the role that Facebook groups play in enhancing the writing performance level and brainstorm ideas at the pre-writing stage. A survey consisting of 10 questions was used to assess these factors. The participants were $42 \mathrm{EFL}$ students at the Department of English Language and Literature. Informants were also required to participate in a Facebook group named "Write out Clear" designed by the researchers. Findings revealed that Facebook groups can be effective in teaching EFL writing. Furthermore, results illustrated that students can develop their vocabulary by being exposed to fellow group members' posts, in addition to checking for misspelled words.

Suthiwartnarueput and Wasanasomsithi (2014) carried out a study focusing on another Facebook-based learning activities, which were grammar and writing discussions for 83 low-intermediate EFL freshmen at a university in Nakhon Pathom Province, Thailand. Based on the participants' questions on Facebook about English grammar and writing, sentence structures, word meanings, parts of speech, and relative clauses were common discussion topics. English grammar was also found out to be worth promoting for Facebook discussions as there was a statically significant difference between the gain scores of the pretest and the posttest in grammar and writing parts. According to the interviews, the students showed their positive attitudes towards using Facebook as an effective medium of grammar and writing learning because Facebook with its interactive features provided them with a convenient and helpful means to participate in discussions with their teachers and other users having better grammar knowledge.

\section{Purpose of the Study}

This study aimed at measuring the effect of Facebook on grammar discussion and writing skills in English as a foreign language: ideas and content, organization, voice and style for university students.

\section{Questions of the Study}

This study attempted to answer the following questions:

(1) What is the effect of Facebook on grammar discussion and writing skills in English as a foreign language for university students?

(2) Is there a significant difference between the pretest and the posttest scores on the development of the four specific writing skills: ideas and content, organization, voice, and style?

To answer these questions, the mean scores of the experimental and the control group in an EFL pre and post grammar and writing test were compared using SPSS version20. In addition, the mean scores of the rubric were compared.

\section{Limitations}

The limitation was that the study was conducted with only one section of 60 female students who were divided into 30 as an experimental group and 30 as a control group. Another additional boundary was the running of the study in the second semester of 2016 in one university in Saudi Arabia with undergraduate female students.

\section{Significance of the Study}

Facebook influences students' writing and also helps them understand students' points of view on the use 
of social media in language learning. It offers insight for language educators who need to know how to utilize Facebook as an effective and efficient way to enhance students' academic writing. In addition, this study benefits policymakers in curriculum reform. Once they understand how Facebook impacts EFL college students' learning and writing, they can make proper policies that allow universities to provide higher quality education to a broader base of English language learners.

\section{Methodology}

\section{Participants}

This study was conducted at Oklt Al Sqoor College of Science and Arts at Qassim University in Saudi Arabia with a population of 1,200 students. English undergraduate students are studying writing skills in the eight levels of their study in the college. They started at a basic writing level and move to writing a five-paragraph essay. The college uses high quality writing textbooks from Oxford University Press (Oshima \& Hogue, Writing Academic English, 4th ed., Longman, 2006). At the time of the study, there were five English $\mathrm{Ph} . \mathrm{D}$. and M.A. holders comprising the college who taught writing in the college. In this quantitative, quasi-experimental study, one English writing class (level four) was chosen randomly as an experimental group to discus grammar and write essays via Facebook for a period of three months. Another English writing class (level four) was chosen to be a control group which studies writing in a traditional way.

\section{Instrument of the Study and Material}

The pre-test and post-test was designed by the researcher (see Appendix A). The total score of the test was 98 points and contained two main parts: grammar and writing to be done in one and a half hour. The grammar part was designed in the form of a close test. The total score of the grammar part was 50 points. It consisted of 25 blanks with multiple choices (a, b, c, and d) available for the students to choose. Each blank involved two points. It tested the students' grammatical knowledge in the use of parts of speech, articles and determiners, verb tenses, subject-verb agreement, and passive and active voice. All of these grammatical topics were considered necessary for writing an essay. The writing part provided two topics for students to choose from to write a five-paragraph-essay. It was scored using a rubric which is prepared by the researcher. The test was corrected by two English teachers that do not teach these undergraduate students. The rubric contained the categories of ideas and content, organization, voice and style (see appendix B). The writing rubric which has six different scale criteria including: "does not meet" receives a score of "1", "partially meets" receives a score of "2", "does not fully meet" receives a score of "3", "meets" that receives a score of "4", "more than meets" that receives a score of " 5 ", and "exceeds" that receives a score of "6". The scores were added so that there was a potential total score of 24 on the rubric. The score of the writing part is 48 as the score of the four sections of the rubric was multiplied by two. The scores were analyzed using descriptive statistics (SPSS) version 20. These four different categories: ideas and content, organization, voice, and style scored on the rubric were compared using T-test. Each skill of these was given a score of " 1 " to " 6 " depending on how well the students performed in each one.

\section{Reliability and Validity of the EFL Writing Test}

Since two teachers assessed the EFL grammar and writing test, a Pearson Correlation Coefficient testing for inter-rater reliability was used to assess the consistency of the scores of the two assessors. 


\section{Procedures of the Study}

In conducting this study, the following procedures were followed:

(1) The Facebook URL used in this study was www, Facebook.com/Mervat. It was open for the students from January to May 2016. The students were allowed to post questions on the main page, leave messages, or chant the main page or profile page, or chant with the teacher and her mates on Facebook.

(2) By using an online discussion board, a discussion was held among the students. They discuss the grammatical points which are necessary for writing an essay; discuss their peers' essays for grammar, mechanics, content, and word use. After the students make editing for their peers' essays, they send messages for their teacher for final correction.

(3) There was a training session to help students to be acquainted with using Facebook, making discussion of the grammatical points upon the discussion board and editing their peers' essays.

(4) The coding of the grammar mistakes of this study was based on Gary-Grant and Gingerich (2012), Orman and Purdue Online Writing Lab (n.d.). The Cambridge Dictionaries Online, Dictionary.com, and the Dictionary and Thesaurus Merriam-Webster Online (n.d.) were used to correct the misuse of vocabulary. The coding of Grammar Mistakes is as follows:

I. Misused tenses;

II. Misused singular/plural nouns;

III. Misused vocabulary;

IV. Misused punctuations (commas and periods);

V. Misused articles (determiners): a, an, the;

VI. Misused pronouns, possessive pronouns;

VII. Misused prepositions;

VIII. Misused nouns/adjectives;

IX. Misused verbs;

X. Misused capital letters;

XI. Misspelled words;

XII. Misused infinitive/gerund;

XIII. Misused superlatives.

The participants coded the mistakes according to aforementioned categories. The mistakes have been presented from the most common to the least common.

(5) The college uses high quality writing textbooks from Oxford University Press (Oshima \& Hogue, Writing Academic English, 4th ed., Longman, 2006). The experimental group discusses grammar and writes essays via Facebook for a period of three months while the control group discusses grammar and studies writing in a traditional way.

(6) The experiment began in January 2016 and continued for about three months. The EFL pre grammar and writing test was administered to the control and the experimental groups on January 26, 2016. The purpose of the pretest was to find out the students' background knowledge in English grammar and writing before the treatment. Every week, students in the experimental group were given a topic to write a five-paragraph essay. After few weeks, students get accustomed to Facebook. At the end of the experiment, the post EFL grammar and writing test was administered to the control and the experimental group on April 26. The purpose of the test was 
to find out to what extent the students' English grammar and writing skill improved after using Facebook. The grammar and writing test was scored by the two evaluators. The scores of the two evaluators were used as a benchmark for the final grammar and writing assessment. Additionally, the grammar part was assessed and each of the four sections of the rubric was scored separately (each has six different scale criteria) so that the researcher could determine if any of the writing skills had improved. Then the two parts of grammar and writing were summed up. The scores and the data from the rubric allowed the researcher to determine whether or not the scores had improved since the students began using Facebook.

\section{Results}

Table 1 shows that there is statistically significant difference at 0.05 between the mean scores of the experimental group $(\mathrm{X} 1=20)$ and the control group $(\mathrm{X} 2=11.3)$ in the post-test of writing in favor of the experimental group as indicated by T-value (24.8). This difference may be attributed to the effect of the experimental treatment exemplified in Facebook.

Table 1

Results of the T-test of the Experimental and the Control Group in the Post-grammar and Writing Test

\begin{tabular}{lllllll}
\hline Group & $\mathrm{N}$ & Mean & S.D. & T-value & df & Sig \\
\hline Experimental & 30 & 20 & 1.84 & 24.8 & 29 & \multirow{2}{*}{ sig } \\
Control & 30 & 11.3 & 1 & 29 & 29 \\
\hline
\end{tabular}

Table 2 indicates that there is statistically significant difference between the mean scores of the pre-test $(\mathrm{X} 1=9.47)$ and the post-test $(\mathrm{X} 2=20)$ of the experimental group students in favor of the post-test. Hence, such difference may be due to the effect of the experimental treatment exemplified in Facebook.

Table 2

Results of the T-test of the Experimental Group in the Pre and the Post Grammar and Writing Test

\begin{tabular}{llllllll}
\hline Test & N & Mean & S.D. & T-value & df & Sig \\
\hline Pre & 30 & 9.47 & 1.40 & -84.7 & 29 & sig \\
Post & 30 & 20 & 1.34 & 29 & \\
\hline
\end{tabular}

The above Table 3 shows that there is statistically significant difference in the mean scores of the experimental and the control group students in post-test of all sub-skills of EFL writing in favor of the experimental group as t-value for independent sample is between $(14.00,36.33)$ and proved to be significant at 0.05 (one-tailed) for all sub-skills: ideas and content, organization, voice, and style. This difference between the experimental and the control group students can be attributed to using Facebook.

Table 3

Results of T-test of the Post-test of the Experimental and the Control Group in EFL Writing Sub-skills

\begin{tabular}{|c|c|c|c|c|c|c|c|}
\hline Writing sub-skills & Group & $\mathrm{N}$ & Mean & S.D. & T-value & df. & Sig. \\
\hline \multirow{2}{*}{ 1-Ideas and content } & Experimental & 30 & 3.60 & 0.498 & \multirow{2}{*}{$15.92 * *$} & 59 & \multirow{2}{*}{ Sig } \\
\hline & Control & 30 & 3 & 5.86 & & 59 & \\
\hline \multirow{2}{*}{ 2-Organization } & Experimental & 30 & 3.47 & 0.517 & \multirow{2}{*}{$17.77 * *$} & 59 & \multirow{2}{*}{ Sig } \\
\hline & Control & 30 & 3 & 6.16 & & 59 & \\
\hline \multirow{2}{*}{ 3-Style } & Experimental & 30 & 7.33 & 0.476 & \multirow{2}{*}{$31.72 * *$} & 59 & \multirow{2}{*}{ Sig } \\
\hline & Control & 30 & 3 & 9.46 & & 59 & \\
\hline \multirow{2}{*}{ 4-Voice } & Experimental & 30 & 7.40 & 0.563 & \multirow{2}{*}{$24.44^{* *}$} & 59 & \multirow{2}{*}{ Sig } \\
\hline & Control & 30 & 3 & 10.8 & & 59 & \\
\hline
\end{tabular}


Table 4 shows that there is statistically significant difference between the mean scores of the pre-test and the post-test of the experimental group students in post-test of all skills of EFL writing in favor of the experimental group as t-value for paired sample is between $(9.26,18.63)$ which proved to be significant at 0.05 (one-tailed) for all skills: ideas and content, organization, voice, and style. These differences between the mean scores of pre-test and post-test of the experimental group students can be attributed to the effect of the experimental treatment exemplified in Facebook.

Table 4

Results of the T-test of the Pre-test and the Post-test of the Experimental Group in Overall Writing Sub-skills

\begin{tabular}{|c|c|c|c|c|c|c|c|}
\hline Writing sub-skills & Test & $\mathrm{N}$ & Mean & S.D. & T-value & df. & Sig. \\
\hline \multirow{2}{*}{ 1-Ideas and content } & Pre & 30 & 2 & 6.19 & \multirow{2}{*}{$16.98 * *$} & 59 & \multirow{2}{*}{ Sig } \\
\hline & Post & 30 & 5 & 1.87 & & 59 & \\
\hline \multirow{2}{*}{ 2-Organization } & Pre & 30 & 3 & 7.67 & \multirow{2}{*}{$19.41 * *$} & 59 & \multirow{2}{*}{ Sig } \\
\hline & Post & 30 & 5 & 8.19 & & 59 & \\
\hline \multirow{2}{*}{ 3-Style } & Pre & 30 & 3 & 7.67 & \multirow{2}{*}{$30.06 * *$} & 59 & \multirow{2}{*}{ Sig } \\
\hline & Post & 30 & 5 & 8.96 & & 59 & \\
\hline \multirow{2}{*}{ 4-Voice } & Pre & 30 & 2 & 14.38 & \multirow{2}{*}{$23.48 * *$} & 59 & \multirow{2}{*}{ Sig } \\
\hline & Post & 30 & 5 & 16 & & 59 & \\
\hline
\end{tabular}

Figure 1 shows the results of the t-test of the experimental and the control group in the post-grammar and writing test.

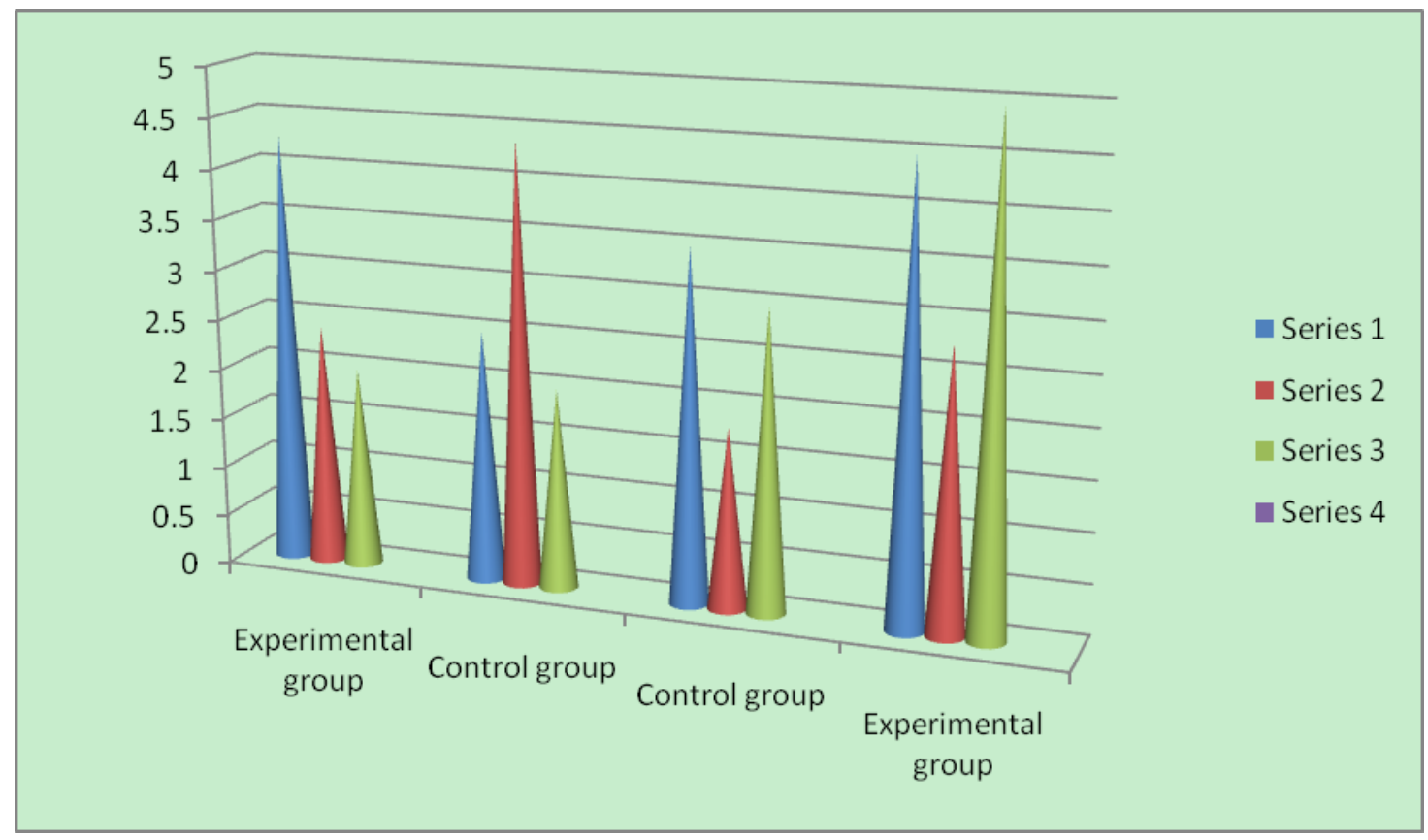

Figure 1. Results of the t-test of the experimental and the control group in the post-grammar and writing test.

Figure 2 shows the results of the t-test of the experimental group in the pre and the post grammar and writing test. 


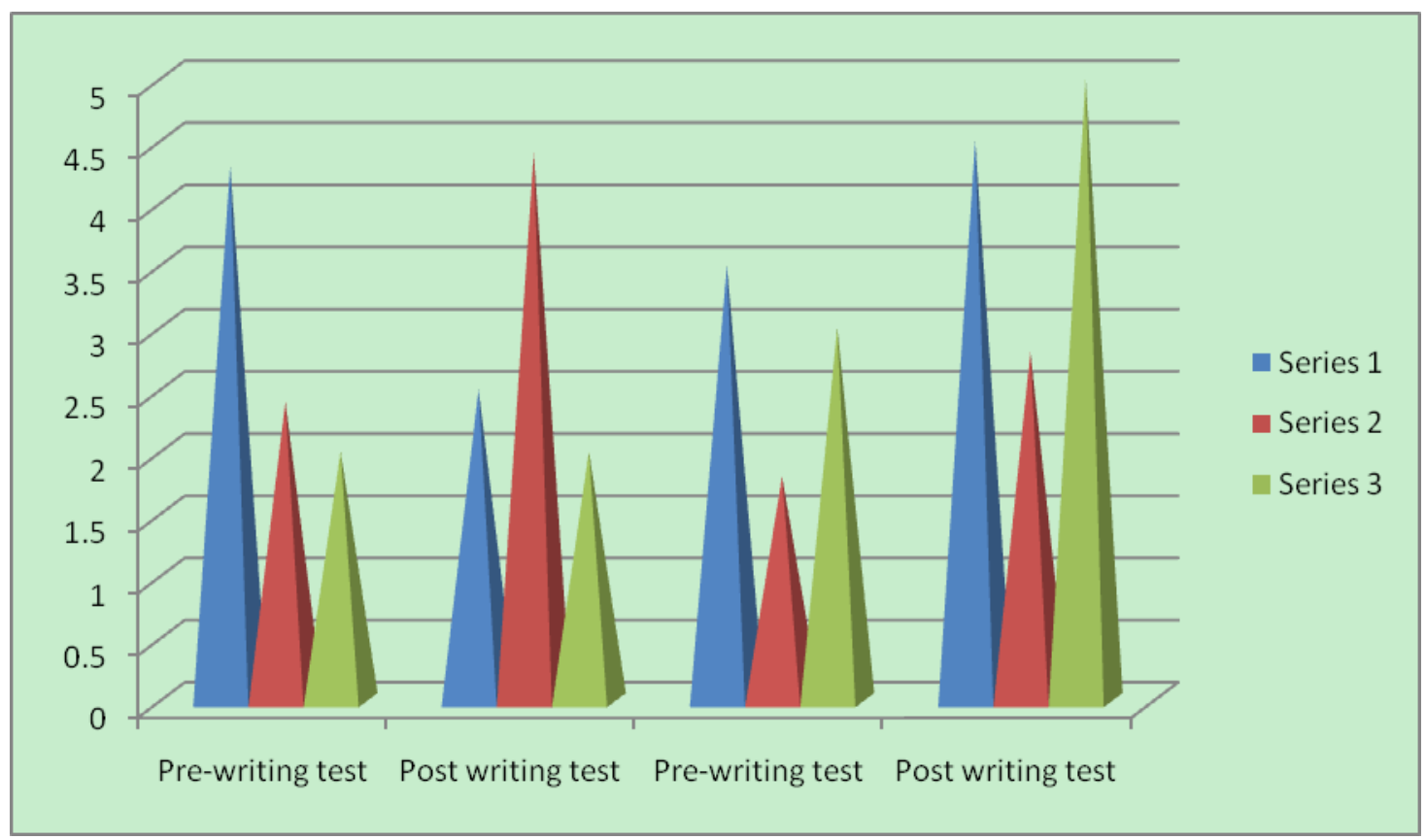

Figure 2. Results of the t-test of the experimental group in the pre and the post grammar and writing test.

\section{Data Analysis}

(1) The students' utterances asking for some explanations in English grammar and writing shown on Facebook were analyzed by using content analysis. It aimed to find out the types of English grammar and writing difficulties the students shared and discussed on Facebook.

(2) The scoring data from the pre-test and the post-test were analyzed by Independent-Samples T-Test. It aimed to compare the students' grammatical and writing competence before and after receiving the treatment.

(3) The item facilities of the multiple choice items of the pre-test and post-test were calculated in order to find out the ability of students in scanning the right answers.

(4) The scoring data from the grammar and writing parts of the pre-test and post-test were analyzed using Pearson Correlation. It aimed to find out to what extent the students' grammatical competence contributed to their writing competence.

(5) To ascertain the reliability of the scoring process of the tests, the grammar and writing parts of the tests were graded by two raters and then the scoring results were analyzed (inter-rater reliability co-efficient $\alpha=0.97$ in the pre-test and $\alpha=0.96$ in the post-test).

\section{Discussion}

From the results, Facebook, as a means for language learning, might develop grammar discussion and writing skill of the EFL students. The students had a higher mean score in the post-test. Grammar discussions seemed to lead to the English writing improvement.

The students' grammatical and writing competence was enhanced after the three-month period when they were given opportunities to use Facebook for discussions. A larger number of students chose the correct items in the grammar part of the post-test. They wrote better using more meaningful contents within a well-organized essay in the post-test. Other than such improvement, the students also prefer this social networking site, 
Facebook. In their opinion, Facebook was an up-to-date learning tool which was easily accessible. It provided convenience and more choices for students to study the English grammar, thus developing their writing competence. They overcame their shyness and dared to ask people questions on Facebook. They could leave messages for the teacher or other Facebook users. They could practice their English writing before they took the writing test.

Additionally, these findings are congruent with previous studies showing that Facebook is an effective medium for language teaching and learning (Mills, 2011; Schwartz, 2009; Solomon \& Schrum, 2007). Shih (2011) reported that the students improved in paragraph organizations, content, vocabulary, spelling, and grammar after receiving Facebook integrated blended learning. The students claimed that Facebook not only facilitated peer assessment but also motivated them to participate more in their language learning. Al-Shehri (2011) found that Facebook built a positive language learning atmosphere and developed the abilities to synthesize ideas and facts from various sources of information.

The findings of the present and previous studies clarify the efficiency of Facebook as a means for language learning. In the present study, the mentioned positive effects resulted from the opportunities to have grammar and writing discussions on Facebook. The present study found that most of the students had discussions about sentence structure on Facebook, and this is possibly one of the reasons that helped them improve their writing competence. This is because sentence structure is an important part of effective writing, and it is also one of the additional criteria essential for the development of academic writing skills (Saunders \& Scialfa, 2003). Moreover, accuracy in sentence structure is concerned with the abilities to develop various types of sentences (Winter, Neal, \& Warner, 1996).

The researcher believes that students' English grammatical competence might contribute to their writing competence, and this hypothesis has been proven true insofar as the results of the study showed the correlations of the gain scores in the grammar and writing parts at significant levels. Similar to the present study, many earlier studies reported that grammar instruction helped the students improve their writing abilities. Pica (1994) found that the students who received clear grammar explanations produced more accurate sentences than those without the instruction. The results of her study in 1994 showed that the instructed students produced more accurate plurals than the uninstructed students since the latter group still kept using a strategy of attaching quantifiers instead of adding "-s" to their nouns like "three book" or "a few house" (Pica, 1994, p. 67). These results seem to shed light on the benefit of grammar instruction since the reduction of errors as well as the ability to identify grammatical rules can bring about better writing competence.

The results of the study are consistent with Kabilan et al. (2010), Shih (2011), and Yunus et al. (2012) that students learned new sentences or new writing structures when they saw friends share feelings and ideas, and when they commented on each other's comments. Students learned grammar and improved their writing skills by (1) reading the comments and posts from their peers; (2) being able to identify their own and their friends' writing mistakes and correct them; (3) discussing incorrect grammar with Facebook friends; and (4) by responding to classmates' comments and post.

Students at the discussion group can use a greater level of grammatical complexity in their writing, and can reduce mistakes; which they are unlikely to be able to do orally in a traditional classroom setting. Each week words written, grammar mistakes, and spelling mistakes were counted. When common grammatical mistakes occurred, they were posted on the group wall for discussion. Then students were asked to find a grammar mistake in a certain line and to correct previous mistakes. At the end of week five, some positive 
improvements in grammar and spelling by students were evident. Students reduced mistakes because they had learned from the posts what mistakes they had made. They were aware of it and used it as grammar advice for further writing.

Based on the results of the present study, the enhancement of the students' grammatical and writing competence resulted from various functions of Facebook that allow the students to discuss, negotiate, collaborate, and share their thoughts with the teacher, their friends, or even other Facebook users. From this perspective, it can be said that such a learning process is related to Social Constructivist Theory. In terms of this theory, Facebook itself can play the role of a community of practice where students can discuss their English grammar and writing difficulties with the teacher or other users. During this process, the teacher or other users can act as more knowledgeable people scaffolding the students to step from their actual stage of development (the position where they can master the task by themselves) to their potential stage of development (the position where they construct new knowledge after having some negotiation, collaboration, and assistance from more knowledgeable people) (Lambert \& Walker, 1996). Consequently, they can construct new knowledge. In other words, the students can enhance their grammatical and writing competence from the assistance of other people through Facebook.

Therefore, Facebook is a Web 2.0 technology that should be promoted and used as an online community for students to discuss their English grammar and writing difficulties. Facebook gives them various options for discussions with the teacher or other users. Facebook allowed them to study at their convenience. They could chat and leave messages or even post their pieces of writing on Facebook for the teacher and other Facebook friends to check them beforehand. Concerning grammar instruction, the results of the correlation analysis revealed that the students' scores in the grammar parts were correlated with their scores in the writing parts. This suggests that their grammatical competence contributed to their writing competence. Thus grammar should be promoted in the teaching of writing.

\section{Conclusion}

Overall, it can be said that students' writing performance was improved with the use of Facebook in collaborative writing. With Facebook, more meaningful learning environment can be created and comment feature makes the learning process more easy and fun. Facebook also allows students to discuss with peers, gives feedback and comment on the writing activities either synchronous or asynchronously.

Therefore, these findings may be beneficial for stakeholders, educators, or writing instructors to utilize collaborative writing in Facebook especially to harness writing skills and change students' perceptions that Facebook is actually appropriate to be medium for English learning. Besides, this study is also hoped to make them to notice the connection between the meaningful communicative use outside the classroom and writing activities that were conducted in a formal setting like classroom context. It is recommended that for future research, a comparison between Facebook and other social networking sites such as Wikis should be made to ascertain which platform is more suitable and effective in improving writing performance. Additionally, a qualitative research also can be conducted in identifying the writing process involved in terms of language structure, writing style, tone, and the likes.

\section{Recommendations}

As presented in this study, grammatical knowledge can bring about the enhancement of writing 
competence. For further research, researchers can explore the effects of other language skills: They can explore the effects of reading on writing improvements of students by uploading some written texts on Facebook. To check comprehension, reading quizzes should be uploaded, followed by writing assignments. The researchers can also upload video files teaching reading skills. With such a trial, they will know whether the students' reading comprehension has any influence on their writing competence.

\section{References}

Abdel-Gawad, N. (2003). Using school journalism for developing some writing skills for secondary stage students (Unpublished M.A. thesis, Faculty of Education, Zagazig University).

Abdel-Razek, T. (2006). The effectiveness of the genre-based approach in developing the writing skills for EFL first year secondary school students (Unpublished M.A. thesis, Faculty of Education, Menoufia University).

Abdou, F. (1993). Developing the writing skill of secondary school students through small groups instruction (Unpublished Ph.D. thesis, Faculty of Education, Zagazig University).

Ajjan, H., \& Hartshorne, R. (2008). Investigating faculty decisions to adopt Web 2.0 technologies: Theory and empirical tests. The Internet and Higher Education, 11(2), 71-80.

Akinbote, R. O., \& Komolafe, A. T. (2010). Explicit grammar strategy and primary school pupils' achievement in written English in Ibadan, Nigeria. European Journal of Social Sciences, 14(1), 61-73.

Al-Shehri, S. (2011). Connectivism: A new pathway for theorising and promoting mobile language learning. International Journal of Innovation and Leadership on the Teaching of Humanities, 1(2), 10-31.

Ashton, J., \& Newman, L. (2006). An unfinished symphony: 21st century teacher education using knowledge creating heutagogies. British Journal of Educational Technology, 37(6), 825-840. Retrieved from http://dx.doi.org/10.1111/j.1467-8535.2006.00662.x

Azar, B. (2007). Grammar-based teaching: A practitioner's perspective. TESL-EJ, 11(2), 1-12. Retrieved from http://www.tesl-ej.org/ej42/a1.pdf

Baran, B. (2010). Facebook as a formal instructional environment. British Journal of Educational Technology, 41(6), E146-E149.

Bartlett-Bragg, A. (2006). Reflections on pedagogy: Reframing practice to foster informal learning with social software. Retrieved January 18, 2013 from http://matchsz.inf.elte.hu/TT/docs/Anne20Bartlett-Bragg.pdf

Benson, P. J., \& Heidish, P. (1995). The ESL technical expert: Writing processes and classroom practices. In D. Belcher and G. Braine (Eds.), Academic writing in a second language: Essays on research and pedagogy (pp. 313-330). Norwood; NJ: Ablex.

Blattner, G., \& Fiori, M. (2009). Facebook in the language classroom: Promises and possibilities. International Journal Instructional Technology and Distance Learning, 17-28. Retrieved March 6, 2013 from https://www.google.com/url?sa=t\&rct=j\&q=\&esrc=s\&source=web\&cd=1\&cad=rja\&ved=0CCwQFjAA\&url=http $\% 3 \mathrm{~A} \% 2 \mathrm{~F}$ \%2Flitu.tu.ac.th\%2Fkm\%2F05-8\%2520Introduction\%2520to\%2520abstract\%2520Writing\%25201.pdf\&ei=ET2wUfz0BMy GrAeIvIHQAQ\&usg=AFQjCNHvYLM786D2gyFS_sv-zY7qckJEcw\&bvm=bv.47534661,d.bmk

Boyd, D. M., \& Ellison, N. B. (2011). Social network sites: Definition, history and scholarship. Journal of Computer-Mediated Communication, 13(1), 210-230. Retrieved $\quad$ March $16, \quad 2011 \quad$ from http://onlinelibrary.wiley.com/journal/10.1111/(ISSN)1083-6101

Duffy, P. (2011). Facebook or Faceblock. In C. McLoughlin and M. Lee (Eds.), Web 2.0 based e-learning: Applying social informatics for tertiary teaching (pp. 284-300). Hershey, PA: IGI Global.

El-Hibir, B., \& Al-Taha, F. (1992). Orthographic errors of Saudi students learning. English Language Learning Journal, 5(1), 85-87.

Ferdig, R. (2007). Examining social software in teacher education. Journal of Technology and Teacher Education, 15(1), 5-10.

Gary-Grant, D. (2012). Citing website. In Top 25 grammar and language mistakes. Retrieved from http://www.prdaily.com/Main/Articles/Top_25grammar_and_langauge_mistakes_10475.aspx

Hadfield, J. (1992). Classroom dynamics. Oxford: Oxford University Press.

Haussamen, B., Benjamin, A., Kolln, M., \& Wheeler, R. S. (2003). Grammar alive! A guide for teachers. Illinois: National Council of Teachers of English. 
Haverback, H. (2009). Facebook: Uncharted territory in a reading education classroom. Reading Today, 27, 1-34. Retrieved from http://www.reading.org/reading-today

Hayashi, P. (2011). A learning success story using Facebook. Studies in Self-Access Learning Journal, 2(4), 309-316.

Herrero, A. H. (2005). Content-based instruction in an English oral communication course at the University of Costa Rica. Actualidades Investigativas en Educación, 2(5), 1-28.

Hinkel, E. (2002). Grammar teaching in writing classes: Tenses and cohesion. In E. Hinkel and S. Fotos (Eds.), New perspectives on grammar teaching in second language classrooms (pp. 181-198). Mahwah, NJ: Erl-baum.

Hinkel, E. (2004). Teaching academic ESL writing: Practical techniques in vocabulary and grammar. Mah-wah, NJ: Lawrence Erlbaum Associates.

Kabilan M., Ahmed, N., \& Abidin, M. (2010). Facebook: An online environment for learning of English in institutions of higher education? Internet and Higher Education, 13, 179-187.

Kwong, V. (2007). Reach out to your students using MySpace and Facebook. Indiana Libraries, 26(3), 53-57.

Lambert, P. E., \& Walker, R. A. (1996). Designing collaborative WWW learning environments - the HENRE project. Retrieved from http://walkerr.edfac.usyd.edu.au/henresite/apwww/apwww-paper-.html

Lampe, C., Wohn, D. Y., Vitak, J., Ellison, N. B., \& Wash, R. (2011). Student use of Facebook for organizing collaborative classroom activities. Computer-Supported Collaborative Learning, 6, 329-347. Retrieved fromhttp://ijcscl.org/

Lave, J., \& Wenger, E. (1991). Situated learning: Legitimate peripheral participation. Cambridge: Cambridge University Press.

Majid, A. H. A., Stapa, H. S., \& Keong, C. Y. (2012). Scaffolding through the blended approach: Improving the writing process and performance using Facebook. American Journal of Social Issues \&Humanities, 2, 336-342. Retrieved from http://www.ajsih.org/index.php/ajsih/index

Maranto, G., \& Barton, M. (2010). Paradox and promise: MySpace, Facebook, and the sociopolitics of social networking in the writing classroom. Computers and Composition, 27(1), 36-47.

Mazman, S. G., \& Usluel, Y. K. (2010). Modeling educational usage of Facebook. Computers \&Education, 55(2), 444-453.

Melor, M. D. Y., Salehi, H., Sun, Ch. H., Yen, J. Y. P., \& Li, L. K. S. (2012). Using Facebook groups in teaching ESL writing, Recent Researches in Chemistry, Biology, Environment and Culture, 75(1), 75-80.

Mills, N. (2011). Situated learning through social networking communities: The development of joint enterprise, mutual engagement, and a shared repertoire. CALICO Journal, 28(2), 345-368.

Nedal, A., Bani-Hani, N. A., Al-Sobh, M. A., \& Abu-Melhim, A. H. (2014). Utilizing Facebook groups in teaching writing: Jordanian EFL students' perceptions and attitudes. International Journal of English Linguistics, 4(5).

Orman, T. (n.d.). Grammar errors. Retrieved from http://ointerest.com/mrsorman/grammarerrors/

Oshima, A., \& Hogue, A. (2006). Writing academic English (4th ed.). Longman.

Oxford, R. L. (1997). Cooperative learning, collaborative learning, and interaction: Three communicative strands in the language classroom. The Modern Language Journal, 81(4), 443-456.

Pazaver, A., \& Wang, H. (2009). Asian students' perceptions of grammar teaching in the ESL classroom. The International Journal of Language, Society and Culture, 27(4), 27-35.

Pica, T. (1994). Questions from the language classroom: Research perspectives. TESOL Quarterly, 28(1), 49-79.

Ping, N. S., \& Maniam, M. (2015). The effectiveness of Facebook group discussions on writing performance: A study in matriculation college. International Journal of Evaluation and Research in Education (IJERE), 4(1), 30-37.

Purdue University Online Writing Lab. (n.d.). Purdue online writing lab. Retrieved from http://www.owl.english.purdue.edu/owl/section/1/4/

Razak, N. A., Saeed, M., \& Ahmad, Z. (2013). Adopting Social Networking Sites (SNSs) as interactive communities among English Foreign Language (EFL) learners in writing: Writing classroom: Strengths and weaknesses. English Language Teaching, 5(8), 1916-4750.

Rifai, R. (2010). Students' attitude on the use of Facebook and blog in writing class and their writing competence. Journal Lingua CUI TURA, 4(1), 25-38.

Saunders, P., \& Scialfa, C. (2003). The effects of pre-exam instruction on students' performance on an effective writing exam. Written Communication, 20(2), 195-212.

Schwartz, H. L. (2009). Facebook: The new classroom commons? The Chronicle Review. Retrieved from http://gradstudies.carlow.edu/pdf/schwartz-chronicle_9-28-09.pdf

Schleppegrell, M. J. (1998). Grammar as resource: Writing a description. Research in the Teaching of English, 32(3), $182-211$. 
Shih, R. C. (2011). Can web 2.0 technology assist college students in learning English writing? Integrating Facebook and peer assessment with blended learning. Australian Journal of Educational Technology, 27(5), 829-845. Retrieved from http://www.ascilite.org.au/ajet/submission/index.php/AJET/inde

Shukor, S. S., \& Noordin, N. (2014). Effects of Facebook collaborative writing groups on ESL undergraduates' writing performance. International Journal of English Language Education, 2(2). doi:10.5296/ijele.v2i2.5868

Solomon, G., \& Schrum, L. (2007). Web 2.0 new tools, new schools. Washington, D.C.: International Society for Technology in Education.

Storch, N. (2005). Collaborative writing: Product, process, and students' reflections. Journal of second language writing, 14(3), 153-173.

Suthiwartnarueput, T., \& Wasanasomsithi, P. (2014). Effects of using Facebook as a medium for discussions of English grammar and writing of low-intermediate EFL students. Electronic Journal of Foreign Language Teaching, 9(2), 194-214.

Wen-Chaun, L., \& Ching, Y. (2011). Exploring students' perceptions of integrating Wiki technology and peer feedback into English writing courses. English Teaching: Practice and Critique, 10(2).

Wenger, E. (1998). Communities of practice: Learning as a social system. Systems thinker, 9(5), 2-3.

Wertsch, J. V., \& Viste, P. T. (2005). L. S. Vygotsky and contemporary developmental psychology. In H. Daniels, Introduction Vygotsky (pp. 57-78). New York: Routledge.

Wichadee, S. (2013). Peer feedback on Facebook: The use of social networking websites to develop writing ability of undergraduate students. Turkish Online Journal of Distance Education, 14(4), 88-103. http://education.waikato.ac.nz/research/files/etpc/files/2011v10n2dial1.pdf

Winter, J. K., Neal, J. C., \& Warner, K. K. (1996). Student and instructor use of comments on business communication papers. Business Communication Quarterly, 59(4), 56-68.

Yancey, K. (2009). Writing by any other name. Principal Leadership, 10(1), 26-29.

Yang, Y. F. (2011). A reciprocal peer review system to support college students' writing. British Journal of Educational Technology, 42(4), 687-700.

Yani, M. (2011). The most common grammar mistakes made by English students when updating Facebook status (A Study Case of English students of Tarbiyah Faculty, IAIN Ar-Raniry). Tarbiyah Faculty IAIN Ar-Raniry Darussalam-BandaAceh.

Yen,Y. C., Hou, H. T., \& Chang, K. E. (2012). Applying Facebook instructional strategy to enhance learners' writing skills in English as a foreign language course. Edulearn 12 Proceedings, 4920-4927.

Yusof, J., AbManan, N. A., \& Alias, A. A. (2012). Guided peer feedback on academic writing tasks using Facebook notes: An exploratory study. Paper presented at The 3rd International Conference on E-Learning ICEL 2011, Bandung, Indonesia. Procedia Social and Behavioral Sciences, 67, 216-228.

Zhao, Y. (2003). Integrating technology and language learning: A literature review and meta-analysis. CALICO Journal, 21(1). 


\section{Appendix A: An EFL Grammar and Writing Test}

Time Allotment: One hour and a half

Part 1: Grammar

A. Read the following passage and choose the best answer ( $a, b, c$, or d).

\section{Overweight}

Being overweight (1) a condition of having more fats than (2) the body's needs. It (3) by many factors, such as eating disorders, metabolic disorders, genetic predisposition, (4) imbalances, alcoholism, limited physical exercise, psychotropic (5) , and stress. To determine whether or not a person is overweight, it (6) by body mass index (BMI) which is a measure of a person's weight taking into account his (7) . To calculate (8) body mass index, the formula states that BMI equals your weight (mass) in kilograms divided by (9) square of your height in meters. If the result of the calculation (10) the BMI of 25 or more, it means that you (11) to be overweight. However, the degrees of overweight by body mass index vary among (12)

races. In the group of Asians, they (13) overweight with (14)

BMI results between 23 and 29.9 while (15) (16) the BMI of 25 or more for being overweight. To lose weight and have a BMI of less than 25 , many people (17) to change (18) lifestyles. One of (19) recommended treatments $(20)$ a controlled diet. However, it was found that such (21) method can have short-term (22) and a person who (23) this way often gains all of the lost weight back and more in the longer term which (24) yo-yo dieting or weight cycling. Thus it is necessary to have physical exercise, long-term planning and weight (25) in conjunction with the controlled die.

\begin{tabular}{|c|c|c|c|c|}
\hline $1-$ & a-nutrition & b-nutrient & c-nutritionally & d-nutritional \\
\hline $2-$ & $a-a$ & b-an & c-the & d-- \\
\hline $3-$ & a-comprise & b-comprises & c-comprising & d-comprised \\
\hline $4-$ & a-proper & b-properly & c-propering & d-propered \\
\hline $5-$ & a-have & b-has & c-having & d-had \\
\hline $6-$ & a-his & b-her & c-its & d-their \\
\hline $7-$ & a-type & b-types & c-typing & d-typed \\
\hline $8-$ & a-need & b-needs & c-needing & d-needed \\
\hline $9-$ & $a-a$ & b-an & c-the & d-- \\
\hline $10-$ & a-depend & b-depends & c-depending & d-depended \\
\hline $11-$ & a-emphasize & b-emphasizes & c-emphasizing & d-emphasized \\
\hline $12-$ & a-have & b-has & c-having & d-had \\
\hline $13-$ & a-your & b-his & c-her & d-their \\
\hline $14-$ & a-uses & b-use & c-are using & d-are used \\
\hline $15-$ & a-participate & b-participates & c-participating & d-participated \\
\hline $16-$ & a-require & b-requires & c-requiring & b-required \\
\hline $17-$ & a-weigh & b-weight & c-weightly & d-weighting \\
\hline $18-$ & a-have & b-has & c-having & d-had \\
\hline $19-$ & a-this & b-that & c-these & d-those \\
\hline $20-$ & a-intake & b-intakes & c-intaking & d-intaken \\
\hline $21-$ & a-keep & b-keeps & c-keeping & d-kept \\
\hline $22-$ & a-fruit & b-fruits & c-fruiting & d-fruited \\
\hline $23-$ & a-is & $b$-are & c-be & d-been \\
\hline $24-$ & a-well-balance & b-well-balances & c-well-balancing & d-well-balanced \\
\hline $25-$ & a-immune & b-immunes & c-immunity & d-immunitie \\
\hline
\end{tabular}


Part 2: Choose one of the following topics and write a five-paragraph-essay about it: Topic one: Making a cake.

Topic two: Community service. 


\section{Appendix B: EFL Writing Rubric}

\section{6-Exceeds:}

\section{Ideas and content:}

-The essay presents a unifying theme or main idea without going off on tangents.

- It stays completely focused on topic and task.

-It includes in-depth information and exceptional supporting facts and details that fully develop the topic.

-It fully explores many facets of the topic.

\section{Organization:}

-The essay presents a meaningful, cohesive whole with a beginning, a middle, and an end (i.e., include an inviting introduction and a strong conclusion).

-The writing progresses in an order that enhances meaning.

-It includes smooth transitions between ideas, sentences, and paragraphs to enhance meaning of text (i.e., have a clear connection of ideas and use topic sentences).

Style:

-The essay includes vocabulary to make explanations detailed and precise, descriptions rich, and actions clear and vivid (e.g., varied word choices, action words, appropriate modifiers, sensory details).

-It demonstrates control of a challenging vocabulary.

-Writing is exceptionally fluent.

-It includes varied sentence patterns, including complex sentences.

-It demonstrates use of writer's techniques (e.g., literary conventions such as imagery and dialogue and/or literary genres such as humor and suspense).

\section{Voice:}

-The essay establishes and maintains a style appropriate to purpose.

-It demonstrates a strong sense of audience.

-It exhibits an original perspective (e.g., authoritative, lively, and/or exciting).

\section{5-More than meets:}

\section{Ideas and content:}

-The essay presents a unifying theme or main idea without going off on tangents.

-It stays focused on topic and task.

-It provides in-depth information and more than adequate supporting facts and details that fully develop the topic.

-It explores many facets of the topic.

\section{Organization:}

-The essay presents a meaningful, cohesive whole with a beginning, a middle, and an end (i.e., include a solid introduction and conclusion).

-The writing progresses in an order that enhances meaning of text.

-It includes smooth transitions (e.g., use topic sentences) between sentences and paragraphs to enhance meaning of text. (Writing may have an occasional lapse.)

Style:

-Essay includes vocabulary to make explanations detailed and precise, descriptions rich, and actions clear and vivid.

-It demonstrates control of vocabulary. 
-The writing is very fluent.

-It includes varied sentence patterns, including complex sentences.

-It demonstrates use of writer's techniques (e.g., literary conventions such as imagery and dialogue and/or literary genres such as humor and suspense).

\section{Voice:}

-The essay establishes and maintains a style appropriate to purpose.

-It demonstrates a sense of audience.

-It exhibits an original perspective (e.g., authoritative, lively, and/or exciting).

\section{4-Meets:}

\section{Ideas and content:}

-The essay presents a unifying theme or main idea. (Writing may include minor tangents.)

-It stays mostly focused on topic and task.

-It includes sufficient information with supporting facts and details that develop the topic. (Details may not be fully developed; ideas may be listed.)

-It explores some facets of the topic.

\section{Organization:}

-The essay presents a meaningful whole with a beginning, middle, and an end despite an occasional lapse (e.g., a weak introduction or conclusion).

-The writing generally progresses in an order that enhances meaning of text.

-It includes transitions between sentences and paragraphs to enhance meaning of text. (Transitions may be rough, although some topic sentences are included.

\section{Style:}

-Essay includes vocabulary that is appropriately chosen, with words that clearly convey the writer's meaning.

-It demonstrates control of basic vocabulary.

-The writing is fluent.

-It exhibits some varied sentence patterns, including some complex sentences.

-It demonstrates an attempt to use writer's techniques (e.g., literary conventions such as imagery and dialogue and/or literary genres such as humor and suspense).

\section{Voice:}

-The essay establishes and maintains a style appropriate to purpose.

-It demonstrates a sense of audience.

-It exhibits an original perspective (e.g., authoritative, lively, and/or exciting).

\section{3-Does not fully meet:}

\section{Ideas and content:}

-The essay attempts a unifying theme or main idea.

-It stays somewhat focused on topic and task.

-It includes some information with only a few details, or list ideas with minimal facts and supporting details to develop the topic.

-It explores some facets of the topic.

\section{Organization:}

-The essay has a beginning, middle, or an end that may be weak or absent. 
-The writing demonstrates an attempt to progress in an order that enhances meaning. (Progression of text may sometimes be unclear or out of order.)

-It demonstrates an attempt to include transitions. (Some topic sentences are used. Transitions between sentences and paragraphs are weak or absent.)

Style:

-The essay contains basic vocabulary, with words that are predictable and common.

-It demonstrates some control of vocabulary.

-The writing is generally fluent.

-It contains mostly simple sentences (although there may be an attempt at more varied sentence patterns).

-It is generally ordinary and predictable.

Voice:

-The essay demonstrates difficulty establishing and maintaining a style appropriate to purpose.

-It demonstrates little sense of audience.

-It generally lacks an original perspective.

\section{2-Partially meets:}

\section{Ideas and content:}

-The essay attempts a main idea.

-It sometimes loses focus or ineffectively displays focus.

-It includes little information and few or no facts and details to develop the topic.

-It explores only one or two facets of the topic.

\section{Organization:}

-Writing has only one or two of the three elements: beginning, middle, and end.

-The writing is sometimes difficult to follow. (Progression of text may be confusing or unclear.)

-Transitions are weak or absent (e.g., few or no topic sentences).

\section{Style:}

-The essay contains limited vocabulary. (Some words may be used incorrectly.)

-It demonstrates minimal control of vocabulary.

-The writing exhibits some fluency.

-It relies mostly on simple sentences.

-It is often repetitive, predictable, or dull.

\section{Voice:}

-Essay demonstrates difficulty establishing a style appropriate to purpose.

-It demonstrates little or no sense of audience.

-It lacks an original perspective.

\section{1-Does not meet:}

\section{Ideas and content:}

-The essay is difficult for the reader to discern the main idea.

-It is too brief or too repetitive to establish or maintain a focus.

-It includes little information with few or no facts and details or unrelated facts and details to develop the topic.

-It is unsuccessful in attempts to explore any facets of the prompt. 


\section{Organization:}

-The writing has only one or two of the three elements: beginning, middle, or end.

-It is difficult to follow, with the order possibly difficult to discern.

-Transitions are weak or absent (e.g., without topic sentences).

Style:

-The essay contains limited vocabulary, with many words used incorrectly.

-It demonstrates minimal or less than minimal control of vocabulary.

-It lacks fluency.

-It demonstrates problems with sentence patterns.

-It consists of writing that is flat and lifeless.

\section{Voice:}

-The essay demonstrates inability to establish a style appropriate to purpose.

-It demonstrates a lack of a sense of audience.

-It lacks an original perspective. 